\title{
Podophyllotoxin-polyacrylic acid conjugate micelles: improved anticancer efficacy against multidrug-resistant breast cancer
}

\author{
Popat S. Kumbhar, Asmita M. Sakate, Onkar B. Patil, Arehalli S. Manjappa and John I. Disouza*
}

\begin{abstract}
Background: Podophyllotoxin (PPT) is a naturally occurring compound obtained from the roots of Podophyllum species, indicated for a variety of malignant tumors such as breast, lung, and liver tumors. This toxic polyphenol (PPT) exhibited significant activity against P-glycoprotein (P-gp) mediated multidrug-resistant (MDR) cancer cells. However, extremely poor water solubility, a narrow therapeutic window, and high toxicity have greatly restricted the clinical uses of PPT. Therefore, the present research was aimed to synthesize the water-soluble ester prodrug of PPT with polyacrylic acid (PAA), a water-soluble polymer by Steglich esterification reaction, and to screen it for assay, solubility, in vitro hemolysis, in vitro release, and in vitro anticancer activity.

Results: The Fourier transform infrared (FTIR) and nuclear magnetic resonance (NMR) spectroscopy results revealed the successful synthesis of podophyllotoxin-polyacrylic acid conjugate (PPC). The assay and saturation solubility of the prodrug is found to be $64.01 \pm 4.5 \%$ and $1.39 \pm 0.05 \mathrm{mg} / \mathrm{mL}$ (PPT equivalent) respectively. The PPC showed CMC (critical micelle concentration) of $0.430 \mathrm{mg} / \mathrm{mL}$ in distilled water at room temperature. The PPC micelles showed a mean particle size of $215 \pm 11 \mathrm{~nm}$ with polydispersity index (PDI) of $0.193 \pm 0.006$. Further, the transmission electron microscope (TEM) results confirmed the self-assembling character of PPC into micelles. The PPC caused significantly less hemolysis $(18.6 \pm 2.9 \%)$ than plain PPT solution. Also, it demonstrated significantly $(p<$ 0.01 ) higher in vitro cytotoxicity against both sensitive as well as resistance human breast cancer cells (MCF-7 and MDA MB-231) after $48 \mathrm{~h}$ of treatment.

Conclusion: The obtained study results clearly revealed the notable in vitro anticancer activity of PPT following its esterification with PAA. However, further in vivo studies are needed to ascertain its efficacy against a variety of cancers.
\end{abstract}

Keywords: Podophyllotoxin prodrug, PAA, Hemolysis, In vitro release, Cytotoxicity

\section{Background}

Cancer or malignancy is a heterogeneous disease characterized by abnormal cell mitosis, and is a serious health concern around the world. Cancer predominance and mortality are expanding year by year and creating a heavier burden globally [1].

Chemotherapy is the most preferred among the available treatment strategies and has been proven to be

\footnotetext{
* Correspondence: johnsir4u@gmail.com

Department of Pharmaceutics, Tatyasaheb Kore College of Pharmacy,

Warananagar, Panhala, Kolhapur, Maharashtra 416113, India
}

effective in clinics. But, the multidrug resistance (MDR) is one of the challenges in the efficient treatment of cancers. A toxic polyphenol podophyllotoxin (PPT) was obtained from the roots of plants from the genus Podophyllum [2] and can be used to treat cancers like breast, lung, and liver cancer and it acts by blocking cell division $[3,4]$. In earlier research papers, it is reported that PPT is capable to kill effectively the MDR (P-gp mediated) cancer cells and therefore used to treat a variety of MDR tumors efficiently [5-8]. However, the clinical applications of PPT are significantly restricted due to its

\section{Springer Open}

(0) The Author(s). 2020 Open Access This article is licensed under a Creative Commons Attribution 4.0 International License, which permits use, sharing, adaptation, distribution and reproduction in any medium or format, as long as you give appropriate credit to the original author(s) and the source, provide a link to the Creative Commons licence, and indicate if changes were made. The images or other third party material in this article are included in the article's Creative Commons licence, unless indicated otherwise in a credit line to the material. If material is not included in the article's Creative Commons licence and your intended use is not permitted by statutory regulation or exceeds the permitted use, you will need to obtain permission directly from the copyright holder. To view a copy of this licence, visit http://creativecommons.org/licenses/by/4.0/. 
enormously poor water solubility, narrow therapeutic window, and high toxicity [9]. Also, chemotherapy of PPT is allied with serious side effects owing to nonspecific distribution and lack of selectivity.

Therefore, to beat the conventional chemotherapeutic drug-related issues, various novel nanoformulations such as nanoparticles, nanocapsules, liposomes, polymer-drug conjugates, and polymeric micelles have been proposed. Currently, the polymer-drug conjugate is a chiefly used strategy wherein the polymers are used to modify the chemical structure of the drug without changing the original medicinal use of the drug [10]. In this strategy, sometimes the hydrophobic drug is conjugated with a hydrophilic polymer or vice versa. These polymer-drug conjugates show improved drug entrapment in the nanoparticles, biopharmaceutical properties, selectivity to tumor cells, tumor cell sensitivity, and in vivo stability [11]. Some researchers have developed a prodrug for different drugs like paclitaxel, docetaxel, and used alone or with different delivery carriers [12-14]. Moreover, Greenwald and co-workers have observed that PPT can be faster released from polymer-drug conjugate prodrug and has stronger inhibition of cell growth [15].

Polyacrylic acid (PAA) is one of the highly hydrophilic, absorbent, and biodegradable polymers with a number of industrial and biomedical applications. It is used widely in modified-release tablets, oral suspensions, and bioadhesive mean for mucosal and oral contact applications [16]. This copolymer is considered as a pharmaceutically safe. Carboxylic acid groups of PAA facilitate further modifications as well as assist binding of small molecules (drugs) and large molecules (biologics) in mild conditions with no structural deterioration. Moreover, it was also reported that non-antigenic PAA increases the immune response upon exposure with sheep erythrocytes, where they worked as an immunostimulants [17]. Thus, the prime objective of the current research was to synthesize the water-soluble ester prodrug of PPT with hydrophilic PAA and to examine its altered in vitro cell growth inhibition characteristics as a result of its improved solubility.

\section{Methods}

\section{Materials and cell culture}

Podophyllotoxin (PPT) was purchased from Shanghai Yuanye Bio-Technology Co., Ltd. (Shanghai, China). Polyacrylic acid (PAA), 4-(dimethylamino) pyridine (DMAP), and $\mathrm{N}, \mathrm{N}^{\prime}$-dicyclohexylcarbodiimide (DCC), were procured from Sigma Aldrich, Mumbai, India. Dimethylformamide (DMF), HPLC grade acetonitrile, methanol, acetone, and water were procured from Molychem, Mumbai, India. All other analytical reagent grade chemicals were used as such without any further processing.

\section{Cell culture}

The cancerous MCF-7 and MDA MB-231(MDR epithelial human triple-negative) breast cancer cells, and noncancerous human embryonic kidney cell line 293 (HEK293) were obtained from ATCC, USA. Dulbecco's modified eagle's medium (DMEM) containing 10\% FBS (fetal bovine serum), $100 \mathrm{IU} / \mathrm{mL}$ penicillin, and $100 \mu \mathrm{g} / \mathrm{mL}$ streptomycin was used to culture both cancerous and non-cancerous cells at $37^{\circ} \mathrm{C}$ in a humidified atmosphere of $5 \% \mathrm{CO}_{2}$.

\section{Ethical approval}

Ethical approval was not applicable.

\section{Synthesis of PPT-PAA conjugates (PPC)}

The synthetic scheme of PPC is presented in Fig. 1. The PPT-PAA ester prodrug was synthesized at a 1:1 molar ratio using the Steglich esterification reaction according to previous reports. Briefly, PAA $(0.0125 \mathrm{mmol}, 25 \mathrm{mg})$ and DMAP $(0.0250 \mathrm{mmol}, 3.05 \mathrm{mg})$ were dissolved in DMF $(5 \mathrm{~mL})$ with stirring for $30 \mathrm{~min}$. The DCC $(0.0250 \mathrm{mmol}, 5 \mathrm{mg})$ and PPT $(0.0250 \mathrm{mmol}, 10 \mathrm{mg})$ were then added under stirring. The reaction mixture was then kept at refrigeration $\left(2\right.$ to $\left.4{ }^{\circ} \mathrm{C}\right)$ for $10 \mathrm{~min}$, and then for $24 \mathrm{~h}$ at room temperature under mild stirring. The precipitated side product dicyclo-hexyl urea (DHU) obtained was removed by filtration, and the filtrate was subjected to dialysis against double distilled water using a pre-activated dialysis bag of 12,000 molecular weight cutoff $(12,000 \mathrm{MWCO})$ for $24 \mathrm{~h}$. After that, the content present in the dialysis bag was isolated by filtration. The filtrate obtained was evaporated under reduced pressure in a rotary evaporator at $70^{\circ} \mathrm{C}$. The obtained product (residue) was then subjected to the confirmation using FTIR and NMR [18].

\section{Characterization of PPC Spectroscopic characterization}

FTIR analysis The structure of PPC was analyzed by FTIR. The FTIR spectra of PPT and PPC were recorded using an Agilent FTIR spectrophotometer (Agilent, Alpha 100508) over the wavenumber 4000 to $400 \mathrm{~cm}^{-1}$.

NMR analysis The ${ }^{1} \mathrm{H}$ NMR analysis was also performed to confirm the structure of PPC. The ${ }^{1} \mathrm{H}$ NMR spectra of the PPT and PPC were recorded by dissolving them in dimethyl sulphoxide (DMSO) using FT-NMR Bruker 300 Avance (300 MHz).

\section{PPC assay}

Briefly, $3 \mathrm{mg}$ of PPC was dissolved in $3 \mathrm{~mL}$ of methanol to get a stock solution concentration of $1000 \mu \mathrm{g} / \mathrm{mL}$. This solution was then allowed to sonicate for 5-10 min and finally analyzed by a UV-visible spectrophotometer at $290 \mathrm{~nm}$ against methanol as a blank solution [18]. 
<smiles>COc1cc(C2=C3CC4C(=O)OCC4[C@@H](O)C4=CC5OCOC5C4=CC3OC2)cc(OC)c1OC</smiles>

PPC

Fig. 1 Synthetic route of PPC

\section{Aqueous solubility}

The aqueous solubility of PPC was studied by using the rotary shaker method. Briefly, the surplus amount of PPC was added into Eppendorf tube containing $0.5 \mathrm{~mL}$ of double distilled (DD) water and kept on a rotary shaker for $24 \mathrm{~h}$. On completion of $24 \mathrm{~h}$ of shaking, the filtrate obtained by filtration was subjected for analysis (after suitable dilution with DD water) using a UV-visible spectrophotometer at $290 \mathrm{~nm}$ and the PPT content was determined [18].

\section{In vitro hemolysis assay}

The hemolysis test was performed in accordance with our previous report. Briefly, the erythrocyte pellet (RBCs) obtained by $10 \mathrm{~mL}$ of human blood (defibrinogenated) was diluted (with $0.9 \% \mathrm{NaCl}$ solution) to obtain a $2 \%$ solution of RBCs (stored at refrigeration temperature till further use). The prepared PPT and PPC solutions were then added to the RBCs solution $(1 \mathrm{~mL})$, and the volume was adjusted to $5 \mathrm{~mL}$ with sodium chloride $(\mathrm{NaCl})$ solution to obtain 10 and $100 \mu \mathrm{g} / \mathrm{mL}$ PPT and PPC solutions. The above solutions were then stored for $1 \mathrm{~h}$ at $37^{\circ} \mathrm{C}$. After incubation, the solutions were centrifuged (at $1000 \mathrm{rpm}$ for $10 \mathrm{~min}$ ), clear and transparent supernatant was collected and subjected for hemoglobin analysis using a UV-visible spectrophotometer at $420 \mathrm{~nm}$. The positive and negative controls used were de-ionized water and $\mathrm{NaCl}$ solution $(0.9 \%)$, respectively. The $\%$ hemolysis was calculated using the following formula $[18,19]$.

$\%$ Hemolysis $=\frac{\text { Test sample absorbance }- \text { Negative control absorbance }}{\text { Positive control absorbance }- \text { Negative control absorbance }} \times 100$

\section{In vitro cytotoxicity}

The effect of PPT and PPC on the viability of cancerous cells (MCF-7 and MDAMB-231) and non-cancerous cell (HEK-293) was determined by using 3-(4, 5dimethylthiazol-2-yl)-2, 5-diphenyltetrazolium bromide (MTT) dye reduction assay [18]. Briefly, 50,000 cells were transferred to each well of 96-well plates and allowed to adhere and grow. After overnight incubation in a $5 \% \mathrm{CO}_{2}$ and $37^{\circ} \mathrm{C}$ atmosphere, the supernatant DMEM was replaced with $100 \mu \mathrm{L}$ of serially diluted test solutions (PPT and PPC). The 96-well plates were then incubated for $48 \mathrm{~h}$ in a similar environment. Post incubation, the supernatant drug solutions were replaced with the same volume of MTT stock solution prepared in phosphate buffer solution (PBS) $0.6 \mathrm{mg} / \mathrm{mL}$. After $4 \mathrm{~h}$ incubation, the MTT solution was replaced with the same volume of DMSO that dissolves the formazan crystals formed in viable cells. The absorbance of the resultant DMSO solutions was measured at $590 \mathrm{~nm}$ using an ELISA plate reader. The absorbance of the test samples was compared to the absorbance of untreated cells to obtain the dose-response curves, and $\mathrm{IC}_{50}$ values were calculated from the same curves [18].

\section{Critical micelle concentration (CMC)}

The self-assembling of prepared PPC into micelles was determined by the iodine UV-visible spectrophotometric method. The double-distilled water was used to prepare PPC solutions of different concentrations. The prepared test solutions were mixed with a fixed volume $(25 \mu \mathrm{L})$ of potassium iodide/iodine solution and incubated overnight $(12 \mathrm{~h})$ in dark at room temperature. Post incubation, the absorbance of test samples and blank sample (containing no PPC) were measured, against double distilled water as a blank, at $366 \mathrm{~nm}$ [20].

\section{Preparation of micelles}

PPC micelles were prepared using a thin-film hydration technique. Briefly, $2.0 \mathrm{mg}$ of PPC was dissolved in $2 \mathrm{~mL}$ of methanol in a beaker. The PPC film was obtained by evaporating methanol at room temperature. The PPC film was redispersed using a fixed volume of doubledistilled $(10 \mathrm{~mL})$ and using a bath sonication technique. 
Post redispersion, the micellar solution was centrifuged (5000 rpm) to obtain a clear solution free from visible dispersed particles [18].

\section{Characterization of micelles Mean particle size}

The mean particle size and zeta potential of PPC micelles were investigated using Malvern ZS Zetasizer (Malvern Instruments Ltd.) at room temperature $\left(25^{\circ} \mathrm{C}\right)$ and measurements were carried out in triplicate.

\section{Morphology by TEM}

In brief, the test sample (2 drops of micellar solution) was transferred on to a copper grid (nitrocellulose covered) and air-dried for $12 \mathrm{~h}$ at room temperature. Then, the dried test sample was stained using a $2 \% \mathrm{w} / \mathrm{v}$ solution of phosphotungustic acid (negative staining). The sample was then air-dried at room temperature and observed under TEM (TEM, FEI Tecnai T-20ST).

\section{In vitro release study}

The dialysis tube technique was used to determine the in vitro release profile of PPT from the prepared PPC micelles [20]. The results were compared with the release profile of PPT from its dispersion prepared in PBS. Into dialysis tubes $(\mathrm{MWCO}=12000 \mathrm{Da})$, the PPT-loaded PPC micelles and PPT dispersions equivalent to $2 \mathrm{mg}$ of PPT were transferred. The tubes were then placed into beakers containing PBS $(80 \mathrm{~mL})$ of $\mathrm{pH} 7.4$ as release medium. The release medium was maintained at $37 \pm 2{ }^{\circ} \mathrm{C}$ and stirred (150 rpm) during the study. One milliliter of release medium was removed at a predetermined time $(1,2,4,8,16,24$, and $48 \mathrm{~h})$ for analysis. At the same time, a $1 \mathrm{~mL}$ fresh release medium was transferred back to the beakers. The test samples withdrawn were analyzed, following centrifugation and suitable dilutions with release medium, at $290 \mathrm{~nm}$ using a UV-visible spectrophotometer. The release profile of PPT from each formulation was carried out in triplicate. Cumulative \% PPT release was calculated and plotted against time [12].

\section{Statistical analysis}

Data are mentioned as the mean \pm standard deviation of three independent experiments. The statistical analysis was performed by using the GraphPad Prism software version 5 (GraphPad Software, Inc., La Jolla, CA, USA). The results obtained were analyzed by one-way ANOVA. $p<$ 0.05 was considered statistically significant.

\section{Results}

\section{Synthesis and conformation of PPC}

The Steglich esterification reaction was used for the synthesis of PPC. The structure of the PPT prodrug is initially confirmed by FTIR. The FTIR spectra of PPT and PPC are shown in Fig. 2. In the FTIR spectrum of PPT (Fig. 2a), the peak at $2923 \mathrm{~cm}^{-1}$ is the characteristic peak of the benzene ring in PPT. In the FTIR spectrum of PPC (Fig. 2b), the peak at $1116 \mathrm{~cm}^{-1}$ is attributed to the $\mathrm{C}-\mathrm{O}$ stretching vibrations of PAA while the peak at $1735 \mathrm{~cm}^{-1}$ indicates ester group formation with PPT. The obtained result demonstrated that PPC was synthesized successfully.

The structure of PPC is also confirmed with ${ }^{1} \mathrm{H}$ NMR (Fig. 3). The peaks at 5.8-7.0 ppm are assigned to the phenyl groups of PPT (Fig. 3a). In the ${ }^{1} \mathrm{H}$ NMR spectrum of PPC (Fig. 3b), the peaks at 5.5-7.7 ppm are characteristic peaks of the phenyl groups of PPT. Besides, we observed the chemical shift value of $3.2 \mathrm{ppm}$ corresponding to the formation of an ester bond between PPT and PAA. This result also confirmed the successful synthesis of PPC. Further, these results are in accordance with the earlier report [21].

\section{Characterization of PPC}

The assay of PPC was found to be $64.01 \pm 4.5 \%$. The solubility of PPC in water is found to be $1.39 \pm 0.05 \mathrm{mg} / \mathrm{mL}$ (PPT equivalent) [12].

\section{In vitro hemolysis assay}

The positive control (de-ionized water) showed complete $(100 \%)$ hemolysis while very slight or no hemolysis $(0 \%)$ was observed with the negative control $(0.9 \% \mathrm{NaCl})$. The plain PPT displayed less hemolysis $(12.8 \pm 1.7 \%)$ at $10 \mu \mathrm{g} / \mathrm{mL}$ concentrations and more hemolysis (51.7 \pm $6.4 \%)$ at $100 \mu \mathrm{g} / \mathrm{mL}$. In contrast, PPC exhibited significantly $(p<0.01)$ less hemolysis $(6.2 \pm 1.2 \%$ and $18.6 \pm$ $2.9 \%)$ than plain PPT at the same concentration.

\section{In vitro cytotoxicity}

The antitumor activity of plain PPT and PPC was examined using MTT assay against cancerous cells (MCF-7 and MDAMB-231cell), and non-cancerous cell (HEK293). The cytotoxicity of both PPT and PPC is expressed in terms of $\mathrm{IC}_{50}$ value. The $\mathrm{IC}_{50}$ value is the concentration of drug necessary to kill $50 \%$ of incubated cells in a designated time. The $\mathrm{IC}_{50}$ values of both PPT and PPC are depicted in Table 1 . We observed substantially increased cytotoxicity $(p<0.01)$ with PPC (low $\mathrm{IC}_{50}$ values), against both cell lines, in comparison to plain PPT after $48 \mathrm{~h}$ study. On the other hand, both PPT and PPC showed significantly low cytotoxicity $(p<0.01)$ against non-cancerous (HEK-293) cells after $48 \mathrm{~h}$ of incubation when compared to cancerous cells.

\section{CMC of PPC micelles}

The CMC of PPC micelles was found to be $0.430 \mathrm{mg} / \mathrm{mL}$.

\section{Preparation and characterization of PPC micelles}

The mean particle size of PPC micelles measured by Malvern zeta sizer is found to be $215 \pm 11 \mathrm{~nm}$ with PDI of $0.193 \pm 0.006$ (Fig. 4a). The zeta potential of PPC 
$\mathbf{A}$
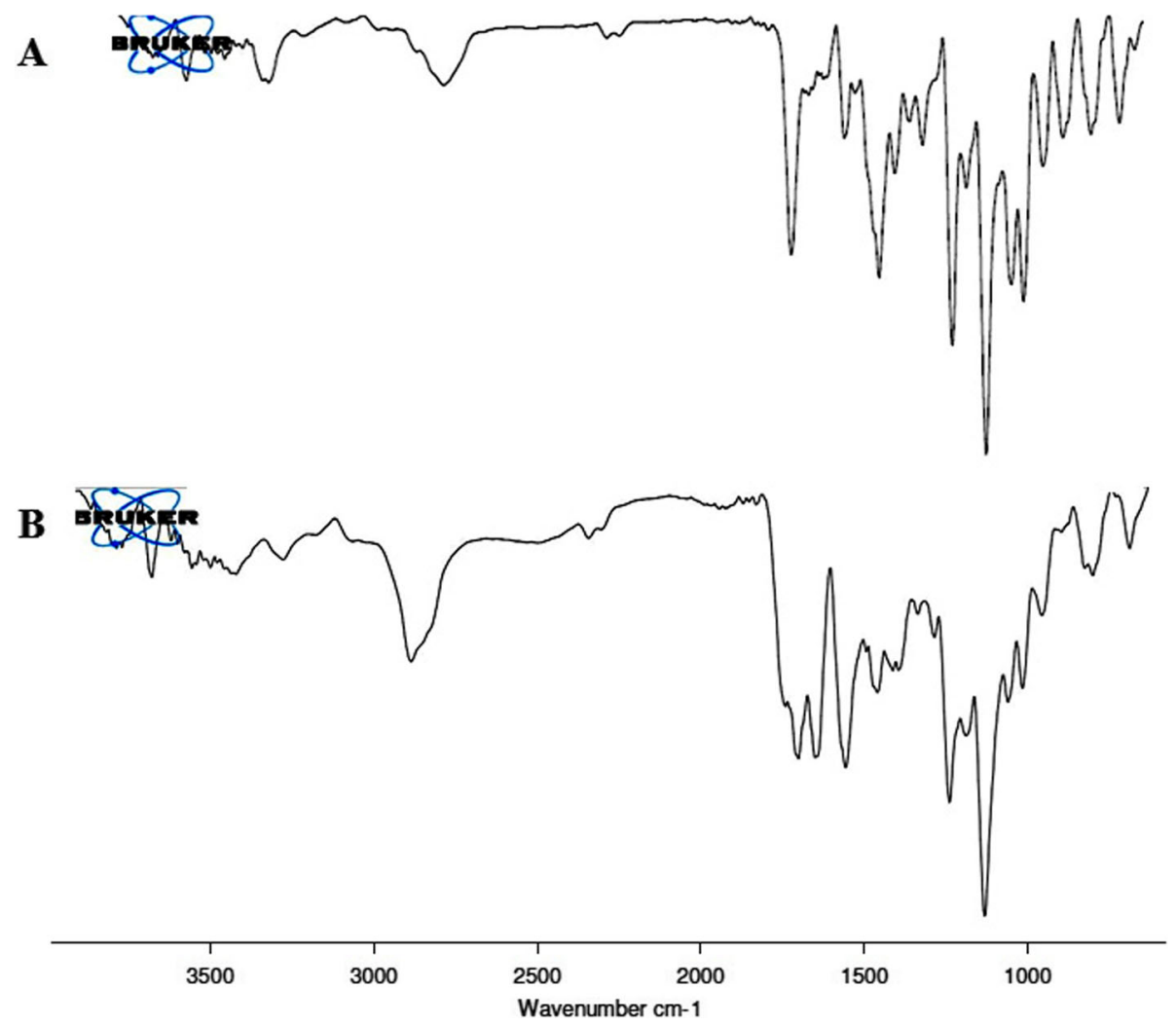

Fig. 2 FTIR spectrum of (a) PPT and (b) PPC

micelles was found to be $-37.3 \mathrm{mV}$. Furthermore, the structure of PPC micelles was confirmed by TEM analysis. The TEM image of self-assembled PPC micelles (Fig. 4b) showed that the micelles are well dispersed and spherical in shape.
In vitro release study

The release profile of PPT from plain PPT solution and PPC micelles is depicted in Fig. 5. Above $90 \%$ of PPT is released from the PPT dispersion in just $4 \mathrm{~h}$. On the other hand, PPT release from PPC micelles is found

$\mathbf{A}$

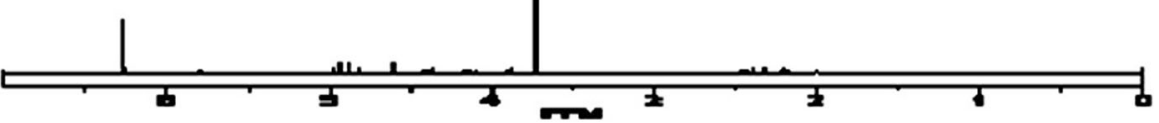

B

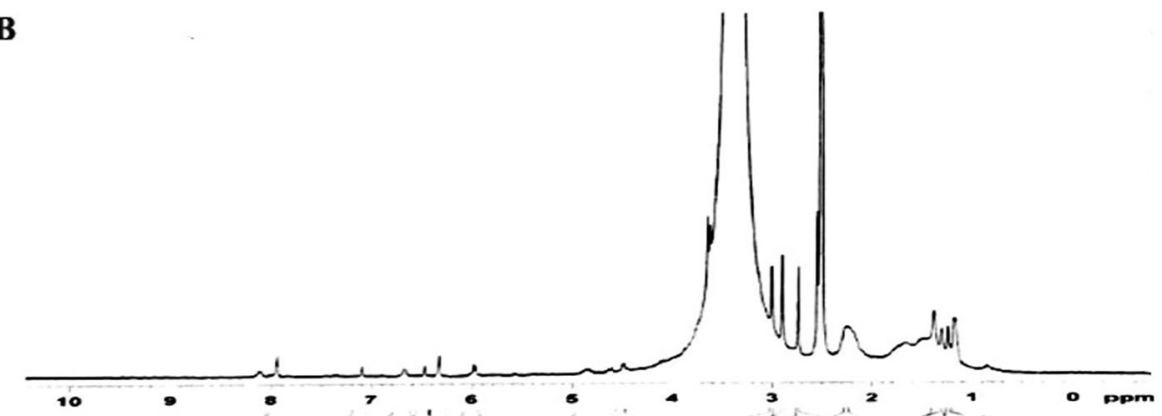

Fig. 3 NMR spectrum of (a) PPT and (b) PPC 
Table 1 Comparison of $\mathrm{IC}_{50}$ values $(\mu \mathrm{g} / \mathrm{mL})$ of tested substances against breast cancer and non-cancerous cell lines

\begin{tabular}{lll}
\hline Cell lines & \multicolumn{1}{l}{$\boldsymbol{C}_{\mathbf{5 0}}$ values $(\boldsymbol{\mu g} / \mathbf{m L})$} \\
\cline { 2 - 3 } & $\mathbf{4 8} \mathbf{h}$ & \\
\cline { 2 - 3 } & Plain PPT & PPC \\
\hline MCF-7 & $1.10 \pm 0.18$ & $0.608 \pm 0.05$ \\
MDA MB-231 & $0.452 \pm 0.06$ & $0.146 \pm 0.02$ \\
HEK-293 & $9.8 \pm 0.56$ & $2.1 \pm 0.26$ \\
\hline
\end{tabular}

Values are mean \pm SD $(n=3)$

significantly $(p<0.01)$ sustained $(35 \pm 3.2 \%$ after 48 h of the study) in comparison to PPT dispersion.

\section{Discussion}

In the current research, the PPC is synthesized via the ester bond formed between the reactive $\mathrm{C}-4$ hydroxyl group of PPT and the carboxyl groups of the hydrophilic polymer, PAA $[13,14]$. The solubility of PPT is found to be about 200-fold higher than the reported standard PPT solubility $(0.001 \mathrm{mg} / \mathrm{mL})$ following conjugation. Thus, the aqueous solubility of PPT following conjugation with PAA is found to increase substantially. The increased solubility of PPT is due to its conjugation with hydrophilic PAA.

The chief prerequisite of any type of nanomedicine is its good compatibility with blood. Plain PPT demonstrated significantly more hemolysis (3.0-fold increased hemolysis) than PPC. The hemolysis test results clearly revealed low or moderate hemolysis by the PPC showing good biocompatibility. Thus, the obtained results suggest that PPC micelles are safe and biocompatible for intravenous injection.

We found 2.0-fold and 3.0-fold higher cytotoxicity of PPC than plain PPT against MCF-7 and MDA MB-231 cells respectively. The significantly enhanced cytotoxic activity of PPC against cancerous cells might be due to endocytosis and increased intracellular accumulation of PPT by nanoparticle uptake. Moreover, the nanometer particle size of PPC micelles and sustained release of PPT from PPC micelles also responsible for the higher cytotoxic activity of PPC. Further, the above results are in accordance with the earlier report [22].

To test the toxicity of PPT and PPC toward healthy cells, in the present study, we also performed the in vitro cytotoxicity study against HEK-293 cells. The obtained results revealed the less cytotoxicity (significantly higher $\mathrm{IC}_{50}$ values) of PPT and PPC toward noncancerous HEK-293 cells as compared to cancerous cells.

The CMC value is a chief parameter used to evaluate the micelle forming ability of block copolymer. It can also reflect the stability of the micelles upon in vivo dilutions. The PPC micelles showed significantly less CMC. These relatively lower CMC of PPC micelles revealed that they would remain stable in solutions even after in vivo dilution [23-25].

The higher mean particle size of PPC micelles could be due to the presence of more PPT-PAA conjugates, which can enlarge the micelles inner hydrophobic core. The PDI value near to zero of PPC micelles suggested the uniform size and homogeneity of the micelles.

The higher release rate of PPT from PPT dispersion could be attributed to its free diffusion through the dialysis membrane into a release medium. PPC micelles demonstrated the sustained release of PPT that could prolong the circulation time and minimize the exposure of PPT to healthy tissues. Furthermore, this behavior could also increase the accumulation of PPT in tumors via the EPR effect and increase the therapeutic efficacy.

\section{Conclusion}

In the current investigation, the water-soluble prodrug of PPT was synthesized by conjugating it with the hydrophilic PAA polymer. The prodrug demonstrated improved water solubility and substantial in vitro cell growth inhibition characteristics. Besides, it demonstrated lower hemolytic behavior which stipulates its
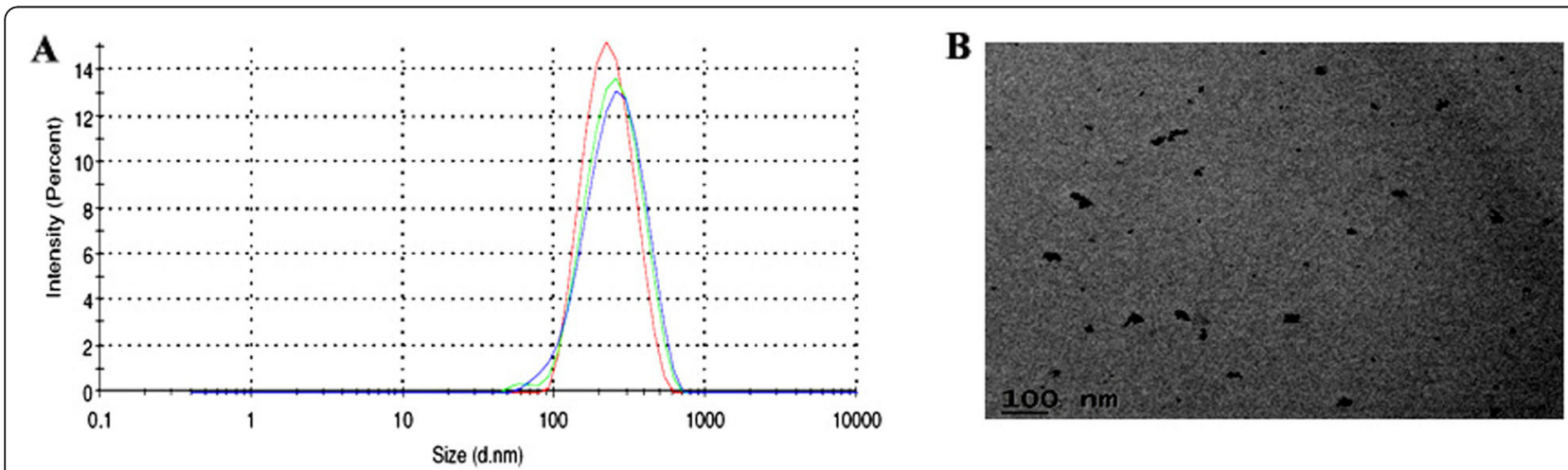

Fig. 4 The mean particle size (a) PPC micelles and (b) TEM image showing self-assembling nature of PPC 


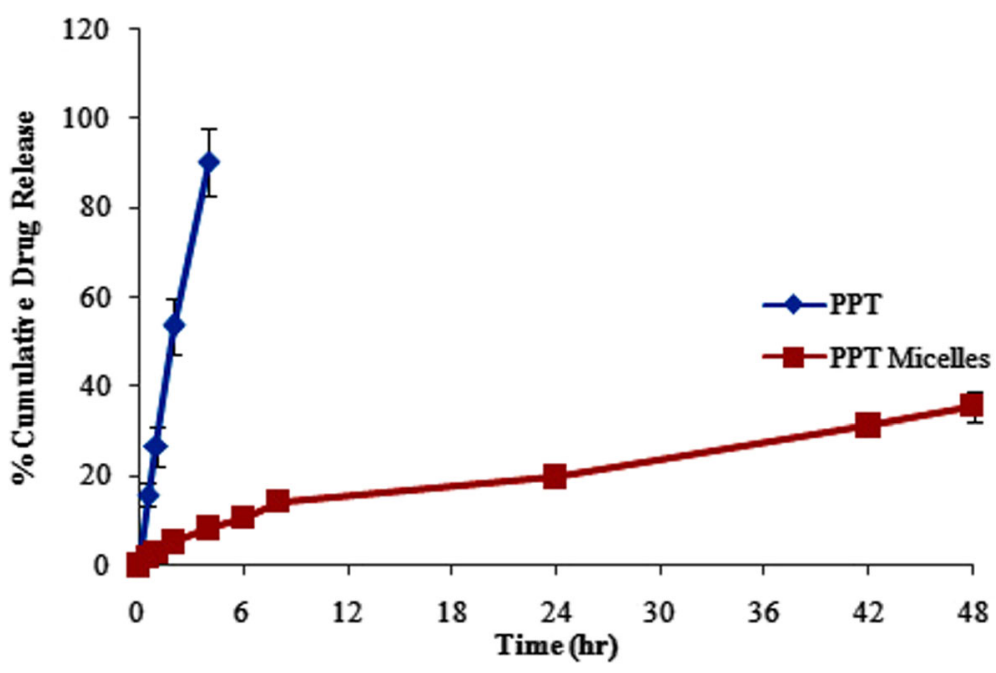

Fig. 5 Cumulative \% of PPT released from the plain PPT solution and PPC micelles

appropriateness for intravenous applications. The marvelous in vitro cytotoxic behavior of prodrug against MDR breast cancer cells indicates its application in the treatment of MDR tumors. The prodrug is found to be self-assembled into micelles with low CMC value indicating its high stability upon systemic dilution. In addition, prodrug micelles exhibited sustained drug release which could cause increased circulation half-life and reduced systemic toxicity. Thus, the current approach could be promising for the efficient treatment of MDR cancers. However, further in vivo studies are needed to validate these obtained in vitro results.

\begin{abstract}
Abbreviations
BCS: Biopharmaceutical classification system; CMC: Critical micelle concentration; DCC: N, N'-dicyclohexylcarbodiimide; DHU: Dicyclo-hexyl urea; DMAP: Dimethylamino pyridine; DMEM: Dulbecco's modified eagle's medium; DMF: Dimethyl formamide; DMSO: Dimethyl sulphoxide; EPR: Enhanced permeation and retention effect; FBS: Fetal bovine serum; FTIR: Fourier transform infrared; MDR: Multidrug resistance; MTT: 3-(4, 5dimethylthiazol-2-yl)-2, 5-diphenyltetrazolium bromide; MWCO: Molecular weight cutoff; NMR: Nuclear magnetic resonance; NaCl: Sodium chloride; PAA: Polyacrylic acid; PBS: Phosphate buffer solution; PDI: Polydispersity index; P-gp: P-glycoprotein; PPC: Podophyllotoxin-polyacrylic acid conjugate; PPT: Podophyllotoxin; TEM: Transmission electron microscope
\end{abstract}

\section{Acknowledgements}

We are greatly thankful to our Head of Institute and Institute Management for supporting this research project.

\section{Authors' contributions}

PK, AS, and OP: Performed all above research activities. PK and AM: Designed, monitored, and coordinated the research activities. JD: Participated in statistical analysis and data interpretation. PK and AM: Involved in the preparation and drafting of the manuscript. All authors read and approved the final manuscript.

\section{Funding}

No funding was received for this project.

Availability of data and materials

All data and materials are available upon request.
Ethics approval and consent to participate

Not applicable

Consent for publication

Not applicable

\section{Competing interests}

The authors declare that they have no conflict of interests.

Received: 27 August 2020 Accepted: 14 October 2020

Published online: 16 November 2020

\section{References}

1. Liang L, Lin SW, Dai W, Lu JK, Yang TY, Xiang Y, et al. Novel cathepsin Bsensitive paclitaxel conjugate: higher water solubility, better efficacy and lower toxicity. J Control Release. 2012;160:618-29.

2. Xue YH, Zhang R, Sun XY, Wang SL. The construction and characterization of layered double hydroxides as delivery vehicles for podophyllotoxins. J Mater Sci Mater Med. 2008;19:1197-202.

3. Fouad Y, Aanei C. Revisiting the hallmarks of cancer. Am J Cancer Res. 2017; 7(5):1016-36.

4. Yu X, Che Z, Xu H. Recent advances in the chemistry and biology of podophyllotoxins. Chemistry. 2017;23(19):4467-526.

5. Roy AM, Ernsting J, Undzys E, Li SD. A highly tumor-targeted nanoparticle of podophyllotoxin penetrated tumor core and regressed multidrug resistant tumors. Biomaterials. 2015;52:335-46.

6. Huicong Z, Shixian L, Dawei Z, Mingxiao D, Xuefei Z, Zhaohui T, Xuesi C. A polypeptide based podophyllotoxin conjugate for the treatment of multi drug resistant breast cancer with enhanced efficiency and minimal toxicity. Acta Biomater. 2018;73:388-99.

7. Subrahmanyam D, Renuka B, Rao CV, Sagar PS, Deevi DS, Babu JM, et al. Novel D-ring analogues of podophyllotoxin as potent anti-cancer agents. Bioorg Med Chem Lett. 1998;8(11):1391-6.

8. Giri A, Lakshmi NM. Production of podophyllotoxin from Podophyllum hexandrum: a potential natural product for clinically useful anticancer drugs. Cytotechnology. 2000;34:17-26.

9. Liu YQ, Yang L, Tian X. Podophyllotoxin: Current perspective. Curr Bioact Compd. 2007;3:37-66.

10. Koziara JM, Whisman TR, Tseng MT, Mumper RJ. In-vivo efficacy of novel paclitaxel nanoparticles in paclitaxel-resistant human colorectal tumors. J Control Release. 2006:112(3):312-9.

11. Manjappa AS, Kumbhar PS, Khopade PS, Patil AB, Disouza JI. Mixed micelles as nano polymer therapeutics of docetaxel: increased in vitro cytotoxicity and decreased in vivo toxicity. Curr Drug Deliv. 2018;15(4):564-75. 
12. Goel PN, Gude RP. Unraveling the antimetastatic potential of pentoxifylline, a methylxanthine derivative in human MDA-MB- 231 breast cancer cells. Mol Cell Biochem. 2011;358(1-2):141-51.

13. Chen C, Yu Y, Wang X, Shi P, Wang Y, Wang P. Manipulation of pH-sensitive interactions between podophyllotoxin-chitosan for enhanced controlled drug release. Int J Biol Macromol. 2017;95:451-61.

14. Wang Y, Huang L, Shen Y, Tang L, Sun R, Shi D, et al. Electrostatic interactions between polyglutamic acid and polylysine yields stable polyion complex micelles for deoxypodophyllotoxin delivery. Int J Nanomedicine. 2017;12:7963-77.

15. Greenwald RB, Conover CD, Pendri A, Choe YH, Martinez A, Wu D, et al. Drug delivery of anticancer agents: water soluble 4-poly (ethylene glycol) derivatives of the lignan, podophyllotoxin. J Control Release. 1999;61(3):28194.

16. Zhang W, Lin W, Pei Q, Hu X, Xie Z, Jing X. Redox-hypersensitive organic nanoparticles for selective treatment of cancer cells. Chem. Mater. 2016; 28(12):4440-6.

17. Murat T, Rabia CK, Sevil DI, Melahat B, Zeynep A, Serhat E, et al. Conjugation, characterization and toxicity of lipophosphoglycan-polyacrylic acid conjugate for vaccination against leishmaniasis. J Biomed Sci. 2013; 20(1):20-35.

18. Manjappa AS, Kumbhar PS, Kasabe R, Diwate S, Disouza Jl. Ameliorated in vitro anticancer efficacy of methotrexate D-a-tocopheryl polyethylene glycol 1000 succinate ester against breast cancer cells. Future J Pharmaceutical Sci. 2019;5(10):1-10.

19. Kumbhar PS, Birange S, Atvale M, Manjappa AS, Disouza Jl. D-gluconic acid based methotrexate prodrug loaded mixed micelles composed of MDR reversing copolymer: in vitro and in vivo results. Colloid Polym Sci. 2018; 296(12):1971-81.

20. Kumbhar PS, Patil NJ, Sambamoorthy U, Disouza JI, Manjappa AS. Simvastatin loaded nano mixed micelles: an approach to treat hormone dependent carcinomas. Int J Pharmaceutical Sci Res. 2019;10(2):546-54.

21. Utsugi T, Shibata J, Sugimoto Y, Aoyagi K, Wierzba K, Kobunai T, et al. Antitumor activity of a novel podophyllotoxin derivative (top-53) against lung cancer and lung metastatic cancer. Cancer Res. 1996;56(12):2809-14.

22. Bromberg L. Polyether-modified poly (acrylic acid): synthesis and applications. Ind Eng Chem Res. 1998:37(11):4267-74.

23. Levy RK, Hall IH, Leex K. Antitumor agents LXII: synthesis and biological evaluation of podophyllotoxin esters and related derivatives. Am Pharmaceutical Assoc. 1983;72:1158-61.

24. Li Y, Chen M, Yao B, Lu X, Zhang X, He P, et al. Transferrin receptor-targeted redox/pH-sensitive podophyllotoxin prodrug micelles for multidrug-resistant breast cancer therapy. J Mater Chem B. 2019;7(38):5814-24.

25. Manjappa AS, Kumbhar PS, Patil AB, Disouza Jl. Polymeric mixed micelles: improving the anticancer efficacy of single-copolymer micelles. Crit Rev Ther Drug Carrier Syst. 2019;36(1):1-58.

\section{Publisher's Note}

Springer Nature remains neutral with regard to jurisdictional claims in published maps and institutional affiliations.

\section{Submit your manuscript to a SpringerOpen ${ }^{\circ}$ journal and benefit from:}

- Convenient online submission

- Rigorous peer review

- Open access: articles freely available online

- High visibility within the field

- Retaining the copyright to your article

Submit your next manuscript at $\boldsymbol{\nabla}$ springeropen.com 